\title{
Stable Formation of Powder Bed Laser Fused 99.9\% Silver
}

\author{
John Robinson ${ }^{1,2}$, Mark Stanford ${ }^{1}$, Arun Arjunan ${ }^{1}$ \\ ${ }^{1}$ School of Engineering, University of Wolverhampton, Telford Innovation Campus, Telford TF2 9NT, UK \\ ${ }^{2} 6$ DME Ltd., Stirchley Road, Telford TF3 1EB, UK
}

\begin{abstract}
Additive manufacture (AM) of metals and alloys using powder-bed fusion (PBF) often employs a 400W (1060 - $1100 \mathrm{~nm}$ wavelength) fibre laser as the primary energy source for Selective Laser Melting (SLM). Highly reflective and thermally conductive materials such as pure silver $(\mathrm{Ag})$ offer significant challenges for SLM due to insufficient laser energy absorption at the powder bed. Accordingly, this work pioneers the processing, analysis, and fabrication of $99.9 \%$ (pure) atomised Ag using PBF AM featuring a $400 \mathrm{~W}$ fibre laser system. The atomised pure silver powder is characterised for its morphology, size, shape, distribution and compared to current AM sterling silver. Laser-powder interaction is then investigated through single track fabrication to assess the feasibility of laser melting pure Ag. Varied process parameter single laser pass and single-track fabrication on both copper and steel build substrates are conducted and analysed with optical and scanning electron microscopy (SEM) techniques. The resulting SLM process parameters are then used to create pure $\mathrm{Ag}$ 3D structures and the effects of laser power, scan speed, hatch distance and layer thickness on material density is evaluated. Furthermore, SEM analysis of the 3D structures was conducted to identify optimum laser power, scan speed, hatch distance and layer thickness required to create dense pure $\mathrm{Ag}$ structures. The results of this study show that SLM processing of pure Ag utilising $\mathrm{PBF}$ AM is feasible. The optimum process parameters required for the generation of controlled track formation and 3D fabrication of pure $\mathrm{Ag}$ at a $97 \%$ density is reported.
\end{abstract}

Keywords: Additive Manufacturing; Selective Laser Melting; Pure Silver; Pure Ag; Particle Analysis; Single Track; Powder Bed Fusion; 99.9\% 


\section{Introduction}

Conventional manufacture of silver $(\mathrm{Ag})$ relies on forging, lost-wax casting, rolling, hand fabrication or machining. Silver classed as a precious metal is highly reflective, thermally and electrically conductive with antimicrobial properties [1-4] and therefore, silver and associated alloys are increasingly being investigated for use in various applications including thermal management, biomedical, renewable energy and electronics [5-7]. Furthermore, traditional manufacturing processes can reduce design freedom and increase material consumption when compared to advanced fabrication techniques such as Additive Manufacturing (AM) [8-10].

Powder Bed Fusion (PBF) is an AM technique used to fabricate complex metallic structures directly from Computer Aided Design (CAD) models [11,12]. However, the interaction between material composition, particle distribution, and morphology concerning laser interaction and the AM processes are not fully understood, particularly with new and emerging materials $[13,14]$ despite the increase in the range of materials covered by the various AM processes $[15,16]$. This is reflected in a recent review carried out by Tufail et al. [17], where further demand for highperformance metallic alloys for automotive, aerospace and electronics industries is also highlighted. Silver as a base and alloying element is expected to have a significant role to play in this aspect due to its unique properties. However, the high reflectivity and thermal conductivity of silver can give rise to challenges for the material to be laser processed by PBF [18] due to laser energy absorption at the powder bed [19]. Accordingly, this paper investigates the feasibility of additively manufacturing pure $\mathrm{Ag}$ using $\mathrm{PBF}$ as a start point for the development of high-performance AM materials for biomedical, renewable energy, electronic and thermal management industries.

Biomedical applications such as orthopaedic implants [20,21] have shown benefits of AM and silver addition. Hengel et al. [3] utilised titanium alloys and AM technologies to fabricate porous orthopaedic implants with embedded silver nanoparticles. The porous AM implants were shown to outperform solid implants of similar geometries showing strong antimicrobial activity without cytotoxicity. Further to this Bradley et al. [7], also describes the benefits of silver addition in the renewable energy and electronic industries.

Gohar et al. [22] investigated the thermal and mechanical properties of copper-aluminium $(\mathrm{Cu}-$ $\mathrm{Al}$ ) alloys with silver addition achieved through sintering. The results of this study showed that the presence of even 2 wt.\% silver in $\mathrm{Al}-\mathrm{Cu}\left(\mathrm{Cu}_{10 \%}\right)$ alloy increased hardness and compression strength while simultaneously increasing thermal conductivity. Furthermore, Sun et al. [1] added Ag to Molybdenum (Mo) and Copper $(\mathrm{Cu})$ sintered powders and investigated the microstructure, electrical and thermal conductivity. Results showed that Ag as an alloying element had a positive effect on both the thermal and electrical conductivity of components. An addition of $1.5 \% \mathrm{Ag}$ 
gave the finest grain size with a desirable homogeneous microstructure whilst increasing thermal and electrical conductivity [1].

The reflective and conductive properties of materials like silver and copper $(\mathrm{Cu})$ are problematic due to poor energy absorption during the SLM process [23]. Pure Cu reflects laser wavelengths of 1000 to $1100 \mathrm{~nm}$ [24]. These wavelengths are used in commercially available PBF systems and can result in absorption $<2 \%$. This can result in insufficient energy absorption for melt pool generation and subsequent weld track production. Colopi et al. [23] conducted investigations utilising a $1 \mathrm{~kW}$ fibre laser to SLM $99.9 \%$ pure $\mathrm{Cu}$ powder. Results concluded that despite the high reflectivity and absorptivity of pure $\mathrm{Cu}$, the $1060 \mathrm{~nm}$ wavelength lasers are feasible for copper PBF components.

Nevertheless, due to high reflectivity, process stability required relatively high laser power of $600 \mathrm{~W}$. Therefore, it has been argued by researchers [23] that the $400 \mathrm{~W}$ fibre lasers found on some conventional PBF systems may not have sufficient laser power to process very reflective and conductive materials such as copper and silver. However, it is important to note that silver reflects $98.8 \%$ laser wavelengths of $650 \mathrm{~nm}$ [25], consequently it is hypothesised that a $400 \mathrm{~W}$ at $1060 \mathrm{~nm}$ wavelength laser fibre may supply the required energy to laser melt pure Ag. While silver as an alloying element is being increasingly studied, the SLM of pure Ag is yet to be demonstrated leaving a significant gap in knowledge.

This work aims to address this gap in knowledge to accelerate the uptake of AM for silver and its alloys to deliver high performance materials and components. In this respect, the study pioneers the evaluation and feasibility of using PBF AM to process pure Ag. The study identifies relevant process parameters and their optimum parametric ranges for both stable single-track and 3D structures of $99.9 \%$ pure Ag. The SLM experiments presented in this paper were carried out on an EOS M290 industrial grade AM system using atomised pure (99.9\%) Ag powder supplied by Legor Group S.p.A. Atomised sterling silver is currently utilised by various companies for SLM application including PBF AM technologies [26]. As such atomised pure and sterling silver powders were analysed using optical and scanning electron microscopy (SEM) for comparison. Subsequently, dynamic image analysis was used to characterise the morphology and particle size distribution of pure Ag. The quality of the resulting pure Ag melt pool and material was then analysed to identify optimum process parameters. Primary research to understand the influence of scan speed and laser power on steel and copper build substrates is also undertaken. Accordingly, this paper reports the optimum laser power and scan speed parameters required for the formation of stable molten material single-track of pure Ag. The validity of these optimum single-track parameters is further analysed to ascertain optimum layer thickness and hatch distance parameters for the fabrication of pure Ag 3D dense structures. 


\section{Material and methods}

\subsection{Powder characterisation}

Powder characteristics such as morphology and Particle Size Distribution (PSD) have a significant effect on powder flowability, packing density and laser-powder interaction [27]. Tan et al. [28] investigated SLM of stainless steel 316L powder with varying laser power, scan speed. and hatch distance. Results concluded that powder PSD and morphology dictated the physical and chemical behaviours of the powder feedstock. Furthermore, PSD is known to directly affect powder packing density and flowability characteristics which subsequently influences the thermal absorptivity and conduction of the powder. The flowability of metallic powder can also change with continued use over time. Deffley et al. [29] reported that used powders often showed poor flowability when compared to new (unused) material and blending unused and used powders improved the powder flowability.

The effect of powder characteristics on SLM processability is critical for the investigations in this study and therefore morphology and PSD were investigated and apparent and tap density recorded. The apparent and tap density of atomised pure Ag used in this study was calculated to be $4.49 \mathrm{~cm}^{3}$ and $5.7 \mathrm{~cm}^{3}$ respectively (following ASTM B964) which is $43 \%$ and $57 \%$ of pure Ag density. As oxygen content has also been shown to have an impact on PBF microstructure, mechanical properties and density $[30,31]$ the moisture content was recorded at $0.68 \%$ using an Adam PMB Moisture Analyser. Furthermore, optical and SEM techniques were utilised alongside dynamic image analysis to confirm the quality of the pure Ag powder used in this study.

\subsection{Laser melting and parametric analysis}

Fig. 1 presents a simplified cross-section of the SLM process considered. The process involves the interaction of material alloying, chemical reactions, heat transfer, material phase transformation and surface tension fluid flow [32]. This study focuses on the effects of AM parameters (laser power, scan speed, hatch distance, layer thickness and build substrate) on the processability of pure silver and the optimum parameter ranges necessary for dense 3D fabrication. The SLM process used in this study features a 400W 1060-1100nm wavelength laser with $100 \mu \mathrm{m}$ spot size capable of fully melting atomised standard AM metals such as titanium, aluminium and nickel alloys.

To evaluate the feasibility of laser melting pure Ag and to identify optimum process parameters the atomised silver powder was laser processed on steel and copper substrates. The common practice for the selection of substrate materials is to use the same substrate as the processing material. However, this was not feasible for this study due to the high cost associated with pure silver. Accordingly, copper was selected due to its high reflectivity and thermal conductivity. 
The steel substrate was used to understand the influence of a build substrate that features a comparatively low thermal conductivity and reflectivity to that of silver.

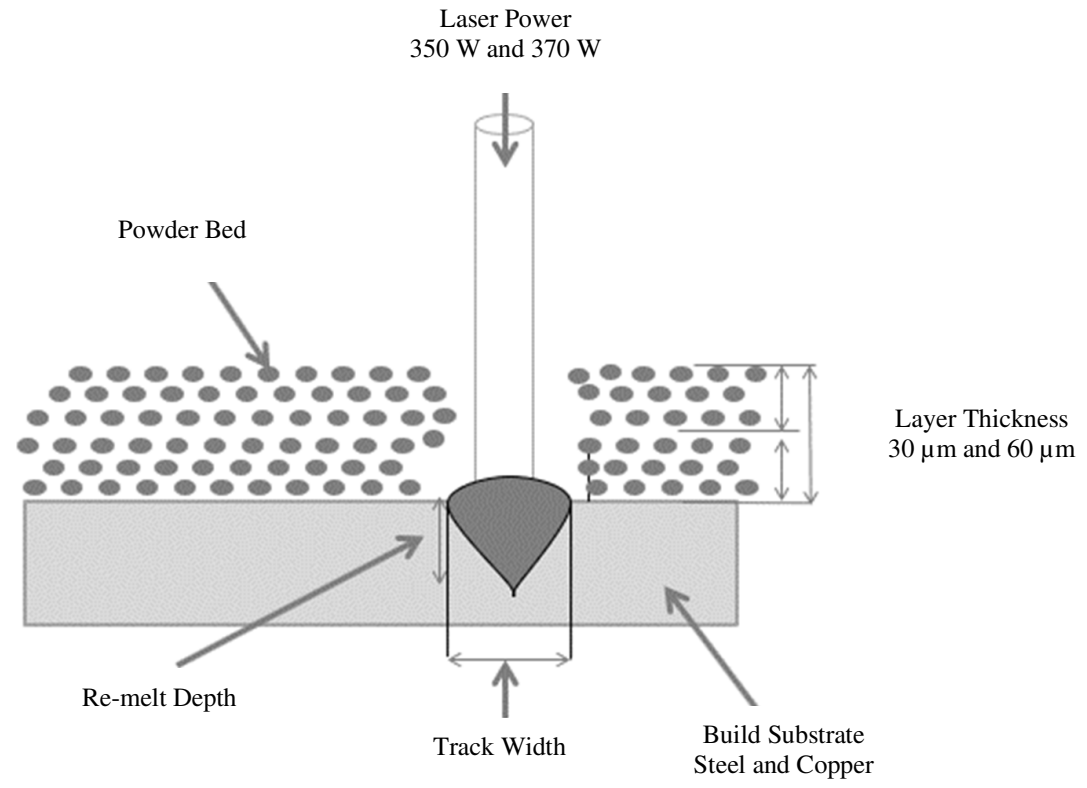

Fig 1. Selective laser melting process and associated variables investigated in this study.

Due to the reflectivity, absorptivity, and conductivity of the atomised pure Ag, laser powers selected for initial investigations were $350 \mathrm{~W}$ and $370 \mathrm{~W}$, which are close to the upper limits of the machine used. Scan speeds were varied from 400 to $1000 \mathrm{~mm} / \mathrm{s}$ at $50 \mathrm{~mm} / \mathrm{s}$ increments: a range selected to maximise energy input while allowing for a realistic fabrication speed. While the lower scan speed $(400 \mathrm{~mm} / \mathrm{s})$ allows for a high energy density input to produce single tracks; higher scan speeds are desirable as they reduce build time making the process more cost-effective. Standard metallic materials such as Aluminium and Titanium feature scan speeds of 800 and $1250 \mathrm{~mm} / \mathrm{s}$ respectively.

Pure Ag single-tracks were fabricated under each of the process parameters using one $30 \mu \mathrm{m}$ layer thickness and one laser pass. The molten tracks were characterised for their maximum, minimum, average and range of bead width. All tests were conducted in an argon environment at an oxygen content of $<0.1 \%$ in the process chamber. The laser melting process began once the build substrates (Copper and Steel) were heated to $35^{\circ} \mathrm{C}$. The inspection of the resulting laser melted tracks was undertaken using an Olympus Lext OLS 3000 Laser Scanning Confocal Microscope (LSCM) and Zeiss Scanning Electron Microscope (SEM).

The optical microscopy results were then used to analyse the molten material and stable track widths to identify optimum laser power and scan speed parameters which resulted in the least track width variation. These results were subsequently used to develop parameters for layer thickness and hatch distance investigations discussed in section 3.6. The AM 3D structures were 
prepared for microscope analysis using pure silver industrial grinding and polishing techniques and methodologies provided by Struers. Images were recorded using optical and scanning electron microscopy and density analysis carried out using Stream Essential software (Olympus).

\section{Results and discussion}

\subsection{Powder morphology}

The optical microscopy data presented in Fig. 2 shows clear differences between the characteristics of atomised pure Ag (Fig. 2a-b) in comparison to sterling silver (Fig. 2c-d). Pure Ag particles are spherical in shape but contain attached satellite particles affecting the powder morphology. Inversely, sterling silver features fewer satellite particles, however, the morphology is more elongated and irregular. Spherical particles are usually desired for the PBF process as it enhances both the packing density and flowability of the powder [28]. As packing density and flowability are affected by powder morphology and PSD, these differences could affect the SLM processing of pure Ag powder.

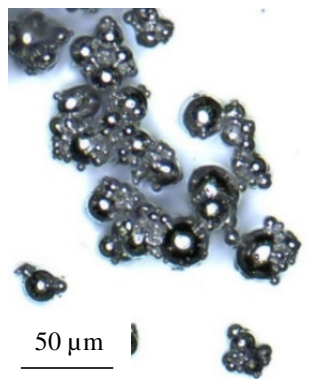

(a)

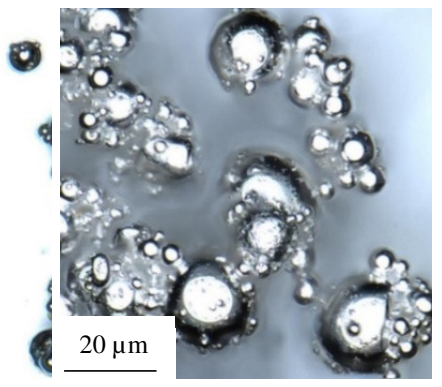

(b)

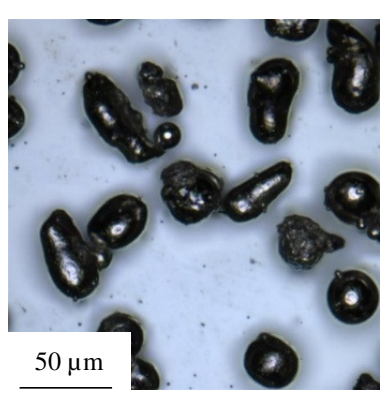

(c)

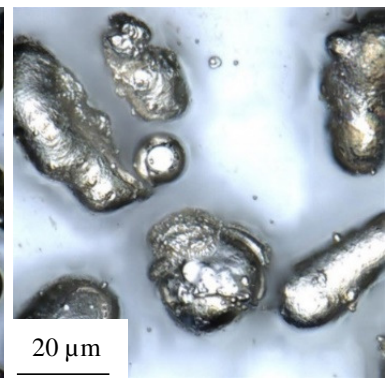

(d)

Fig 2. Optical microscopy results of atomised powder particles for (a) pure Ag at $50 \mu \mathrm{m}$, (b) pure Ag at $20 \mu \mathrm{m}$, (c) sterling silver at $50 \mu \mathrm{m}$ and (d) sterling silver at $20 \mu \mathrm{m}$.

According to Sun et al. [1], small changes in alloying elements can have a significant influence on the powder characterestics of silver alloys. For example, a 1.5 wt.\% addition of $\mathrm{Ag}$ has shown to increase both thermal and electrical conductivity of Mo-Cu powders [1]. To analyse particle morphology and the satellite particle interface, further analysis was carried out using SEM for both atomised pure Ag and sterling silver powders. The resulting data as shown in Fig. 3 confirms the presence of a relatively high number of satellite particles (Fig. 3a) in pure Ag powder but 
also highlights the uniform spherical shape of the larger particles. Small satellite particles below $2 \mu \mathrm{m}$ in diameter are attached to the larger spherical particles making them irregular in shape (Fig. 3b). These satellite particles can reduce the powders flowability and also affect the powders packing density, which in turn could affect the materials SLM processability [28].

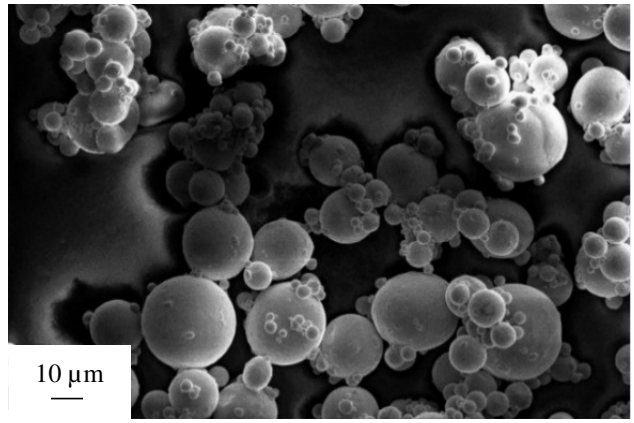

(a)

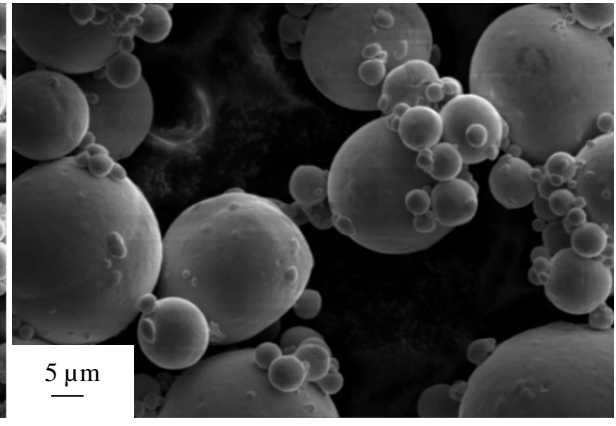

(b)

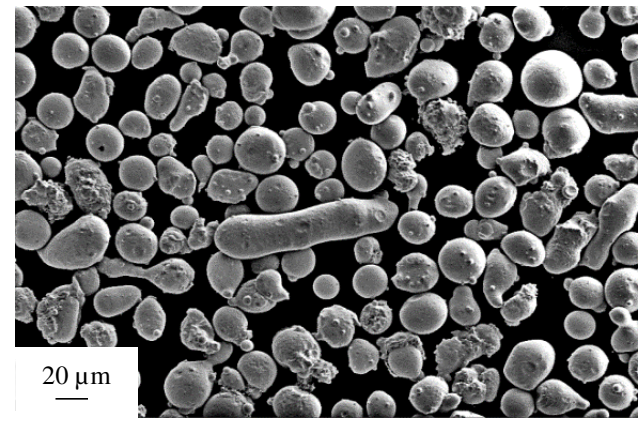

(c)

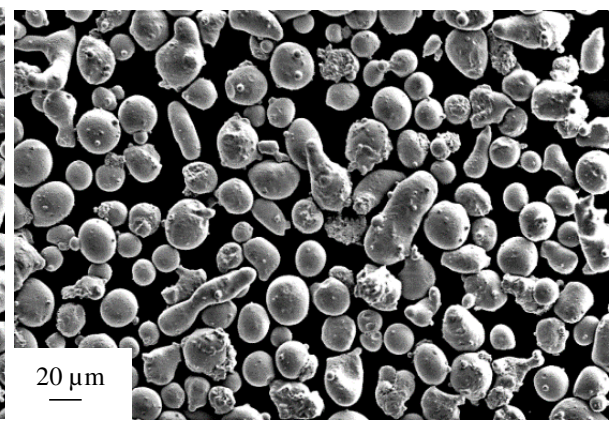

(d)

Fig 3. Scanning Electron Microscopy images of (a) pure Ag particles at 10um showing satellite particle size variability (b) pure Ag at $5 \mu \mathrm{m}$ showing minimal adhesion area between host and satellite particles (c) sterling silver

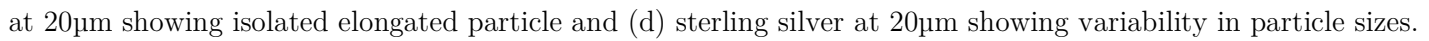

Fig. 3c highlights the elongated particle size and shapes present in the sterling silver powder in addition to the presence of satellite particles and irregular morphology (Fig. 3d). Spherical particles are usually desired to enhance powder flowability, while optimum PSD enhances the powder packing density and thermal absorptivity [28]. Pure Ag despite the higher satellite particle content, has uniform spherical shape, however flowability may be affected by the presence of satellite particles. While studying the particle size of the sterling silver itself is outside the scope of this study, the comparison highlights the differences in morphology of pure Ag and current silver AM alloys.

Due to the relatively large number of satellite particles present in pure Ag, dynamic image analysis was carried out to further investigate the particle morphology. A Retsch Technology Camsizer x2 having a $1 \mu \mathrm{m}$ resolution was used to study the particle width/length ratio. Powder samples were fed through a feed channel ensuring all particles fell through the measurement field and two digital cameras were used to record the data at 300 frames per second. When the basic 
camera (CAM-B) recorded the relatively large particles, the zoom camera (CAM-Z) recorded the smaller ones. A contact-free laser diffraction technique was used to automatically capture particle size and shape information.

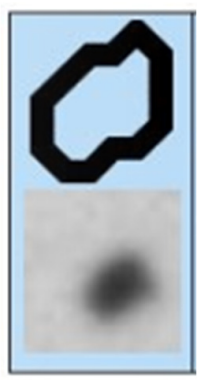

$\mathrm{X}_{\text {max }}=0.0649 \mathrm{~mm}$ $\mathrm{X}_{\min }=0.0518 \mathrm{~mm}$ $X_{\text {area }}=0.0575 \mathrm{~mm}$

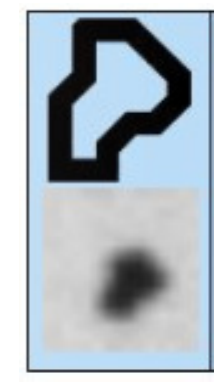

$\mathrm{X}_{\max }=0.0642 \mathrm{~mm}$ $X_{\min }=0.0464 \mathrm{~mm}$ $X_{\text {area }}=0.0576 \mathrm{~mm}$

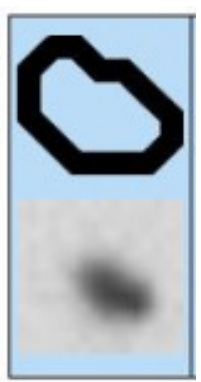

$\mathrm{X}_{\max }=0.0646 \mathrm{~mm}$ $X_{\text {min }}=0.0506 \mathrm{~mm}$ $\mathrm{X}_{\text {area }}=0.0581 \mathrm{~mm}$

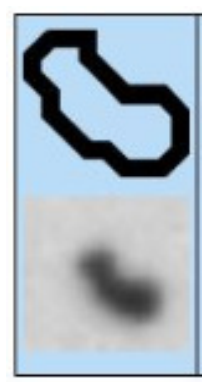

$\mathrm{X}_{\max }=0.0897 \mathrm{~mm}$ $X_{\text {min }}=0.0564 \mathrm{~mm}$ $\mathrm{X}_{\text {area }}=0.0710 \mathrm{~mm}$

Fig 4. Atomised pure silver particle morphology characteristics.

Fig. 4 shows the typical atomised particle size and shape of the pure Ag powder, where $\mathrm{X}_{\max }$, $\mathrm{X}_{\min }$, and $\mathrm{X}_{\text {area }}$ are the particle length, width and equivalent circular surface area. The result shows that most particles are over $60 \mu \mathrm{m}$ long with the largest $X_{\max }$ value being $89.7 \mu \mathrm{m}$. However, the width $\left(\mathrm{X}_{\min }\right)$ of the particles is around the $50 \mu \mathrm{m}$ sieve range. The results show irregular shaped particles, which can be explained by the presence of satellite particles as shown in Fig. 2 (a-b) and Fig. 3 (a-b).

The overall particle size distribution (PSD) shown in Fig. 5 can affect flowability and packing density of the powder. Pleass et al. [33] analysed the chemical composition, PSD and flowability of three nickel-based alloy powders for SLM. The analysis concluded that a large volume of fine particles can render metallic powder unusable for PBF technologies due to the strong cohesive forces negatively affecting the powder flowability. Accordingly, the results from the particle analyser were used to distinguish the mode, mean, median and volume fractions $\left(\mathrm{D}_{10}, \mathrm{D}_{50}\right.$, and $\mathrm{D}_{90}$ ) to identify the Particle Volume Distribution (PVD) as shown in Fig. 5a. The data was used to establish excessively high or low particle distribution that can affect the powders processability for PBF.

The PVD analysis concluded a $\mathrm{D}_{10}$ of $18.8 \mu \mathrm{m}, \mathrm{D}_{50}$ of $27.6 \mu \mathrm{m}$ and $\mathrm{D}_{90}$ of $38.6 \mu \mathrm{m} . \mathrm{D}_{50}$ represents the median value; meaning, $50 \%$ of powder particles were less than $27.6 \mu \mathrm{m}$ in size. With a $\mathrm{D}_{10}$ and $\mathrm{D}_{90}$ of 18.8 and $38.6 \mu \mathrm{m}$; the results showed that the PVD is relatively even with only $10 \%$ of particles below $18.8 \mu \mathrm{m}$. The reasons for this can be explained using Fig. 2 and 3, where the smaller satellite particles can be seen attached to the larger spherical particles post-atomisation. A $D_{90}$ of $10 \mu \mathrm{m}$ can result in unusable powder for PBF processing as described by Pleass et al. [33]. In comparison, the PSD shown in Fig. 5b suggest that the atomised pure silver powder measured in this study has a near normal size distribution and is suitable for PBF AM. 


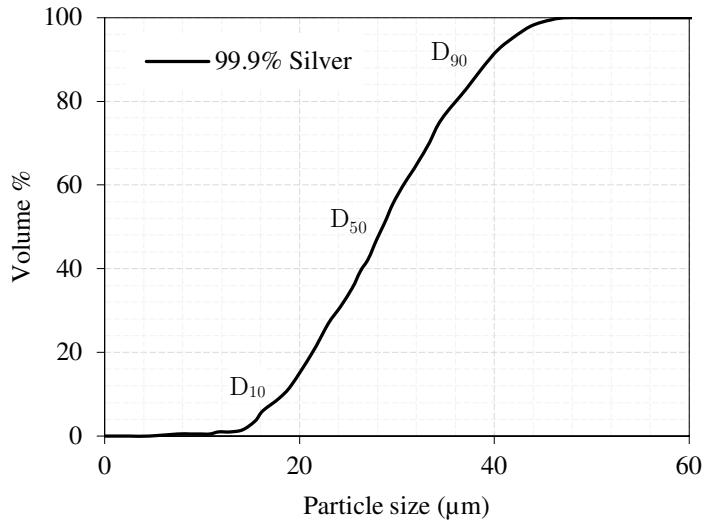

(a)

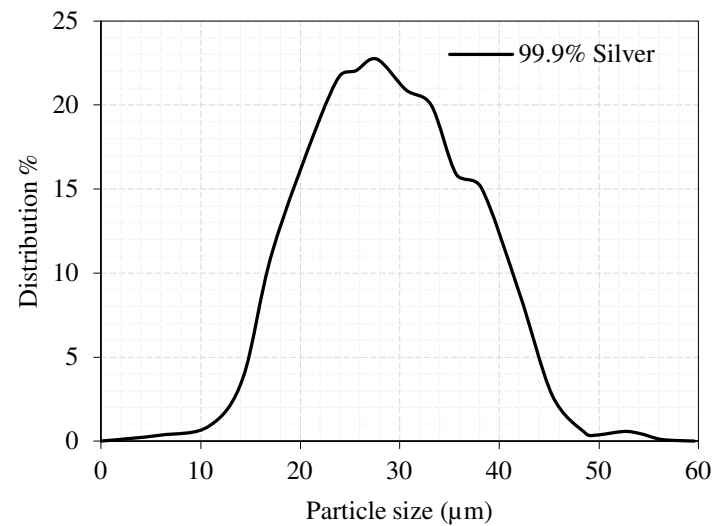

(b)

Fig 5. Particle analysis of atomised pure Ag sieved at $50 \mu \mathrm{m}$ (a) Particle Volume Distribution (PVD) and (b) Particle Size Distribution (PSD).

\subsection{Single track fabrication using SLM}

The PBF process is reliant on a range of parameters that are related to feedstock, build process, laser setting, material interactions, and melt-pool variables totalling in excess of 130 variables. O'Regan et al. [34] describes the process parameter variables and relations to SLM component dimensional tolerances, surface roughness and porosity. The study concluded that process variables can affect the residual stresses and density of the component. Tan et al. [28] reported that laser power and scan speed are controllable process parameters, which affect the energy density input at the powder bed. This in turn contributes to material energy absorption, subsequently affecting both the binding and melting mechanisms. Therefore, it is clear that the mechanical properties of the SLM components will be a result of molten material single-track in addition to the layer-by-layer bonding interactions.

The interactions of molten material single tracks and the connection between layers has a significant impact on the microstructure and structural integrity of the material produced; thereby affecting the component quality. From the investigations of Aversa et al. [35] on singletrack aluminium alloys, it was observed that laser power and scan speed have a significant effect on laser energy absorption, heat transfer and phase transformation and therefore stable molten track production. During SLM, part of the laser energy is absorbed by the particles at the top surface of the powder layer. Tan et al. [28] describes the thermomechanical reaction as the laser energy penetrates the underlying particles, where the intensity decreases as the heat transfers through the layers. When the laser scans over the atomised pure Ag powder, it melts the material and creates a molten powder track as shown in Fig 6. The Surface tension causes the molten tracks to form a cylindrical or keyhole cross-section as described in Fig 1. 


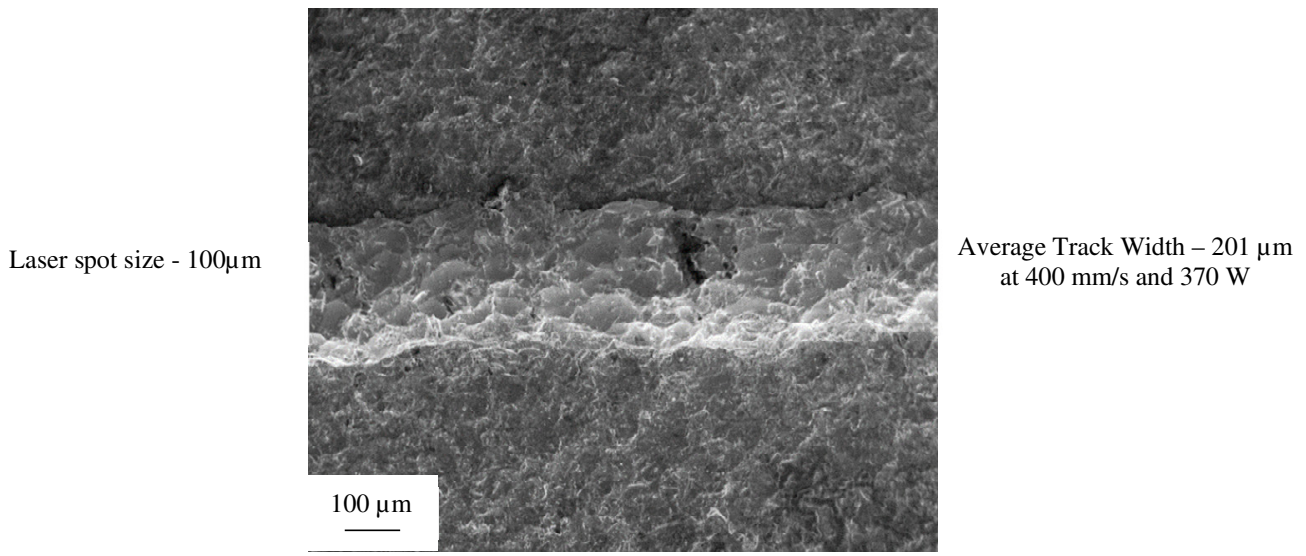

Fig 6. SEM image of pure Ag single-track using SLM

The size of the track produced is a function of the absorptivity and reflectivity of the material being melted and the energy input to the weld pool. Increasing the scan speed reduces laser energy input, which in this study resulted in a smaller weld pool and track width represented by the discontinuous molten material track shown in Fig 7 . The features and stability of each track can be associated to the laser power, scan speed and powder layer thickness in addition to the physical properties and geometry of powder particles. Melt depth also varies depending on the absorptivity and reflectivity of the powder, laser power, scan speed and the thermal conductivity of the substrate. Consequently, at lower scan speeds, the temperature and volume of the powder consumed is higher as a result of the higher energy input.

Incorrect or unoptimised SLM parameters can lead to unwanted effects such as instability (Fig. 7a) or balling (Fig. 7c) of the molten material tracks leading to poor interlayer bonding and the formation of porosity. Studies by Guo et al. [36] on single-track fabrication of Niobium (Nb) and Titanium (Ti) alloys showed that track width and substrate penetration increased as laser energy density increased. Accordingly, inconsistent molten material and track fabrication was shown to increase as laser energy density decreased.

Balling on the other hand is a result of low energy densities and insufficient contact of molten material with the solid substrate. Inadequate laser power causes a deficiency of laser energy that is required to penetrate the powder bed to melt the powder and substrate. This results in instability of the molten track resulting in inconsistent track formation as shown in Fig. 7 . Instability can also occur at lower scan speeds where turbulence in the weld pool leads to inconsistencies in the weld beads. On the contrary, excessively high scan speeds cause a balling effect due to the limited energy input as demonstrated in Fig 7c. Accordingly, it can be seen that a range of optimal parameters are required for the SLM process in order to achieve powder bed and substrate penetration for the formation of stable and continuous pure Ag molten tracks (single-track), which this study aims to identify. 


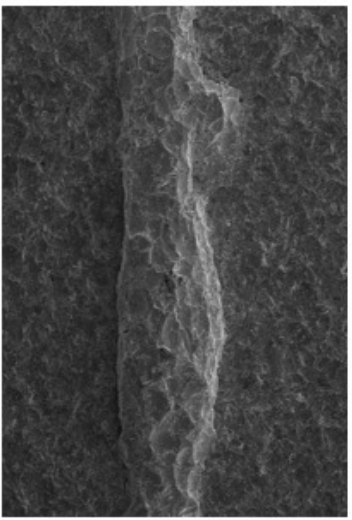

(a)

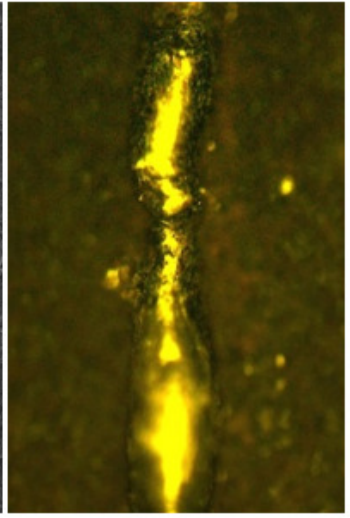

(b)

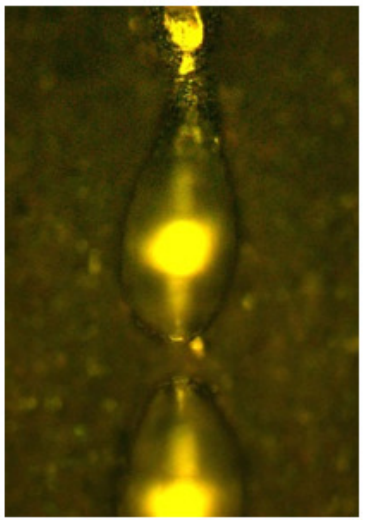

(c)

Fig 7. Laser melted pure Ag single tracks showing (a) SEM data of track instability caused by insufficient energy input (b) optical microscopy images of track instability caused by insufficient energy input and (c) balling effect caused by insufficient energy input.

\subsection{Influence of substrate material}

The industry standard is to use a build substrate material that is equivalent to powdered material being processed. This not only ensures continuity between initial layers of the building process but also prevent alloy contamination along the initial build layers. However, for precious metals, like pure Ag, a $250 \times 250 \mathrm{~mm}$ solid substrate is unfeasible due to the high associated cost. Consequently, initial laser melting of pure silver was experimented on copper and steel substrates. When compared to silver, the reflectivity and thermal conductivity of a copper substrate is a closer representation of pure silver laser interaction. Furthermore, a copper substrate better simulates pure silver track and pure silver layer-by-layer interactions, once layer build height has reached beyond the thermochemical effects of the substrate.

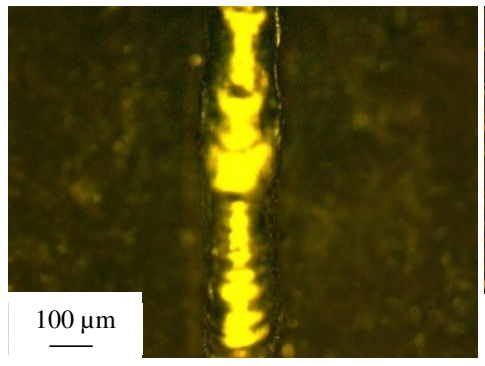

(a)

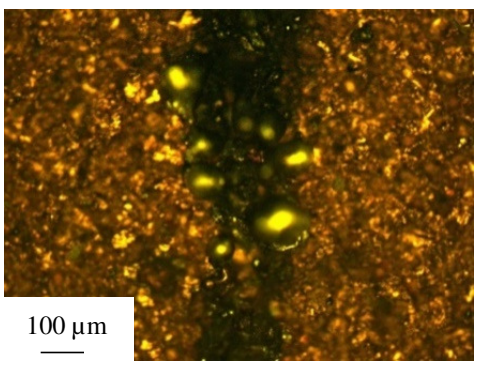

(b)

Fig 8. Laser melting of pure silver at $370 \mathrm{~W}$ laser power and $400 \mathrm{~mm} / \mathrm{s}$ scan speed on (a) steel and (b) copper substrates.

Fig 8 shows the single-track SLM fabrication of pure silver powder on steel and copper substrates at a laser power and scan speed of $370 \mathrm{~W}$ and $400 \mathrm{~mm} / \mathrm{s}$ respectively. These parametric values refer to the highest laser power and slowest scan speed considered in this study and therefore the maximum energy input at the powder bed. The result in Fig 8a shows that fully molten 
single-track fabrication is feasible with pure $\mathrm{Ag}$ on a steel substrate using the selected parameters. However, no single-track formation or molten material was achieved on a copper substrate under the same conditions (Fig 8b). This demonstrated that when laser melting pure $\mathrm{Ag}$, the properties of the substrate material have a significant influence on single track formation. It is clear that the energy input at the powder bed is insufficient for wetting silver on highly conductive copper substrate, which can be attributed to the laser energy being reflected and dissipated.

In comparison Fig 9 presents single track fabrication of pure silver at lower laser power of $350 \mathrm{~W}$ and $400 \mathrm{~mm} / \mathrm{s}$ scan speed. A molten material single track is produced for and pure silver (Fig 9a) on steel substrates. However, similar to the previous case, pure silver on a copper substrate failed to create a molten track and only partially molten powder can be seen (Fig 9b).

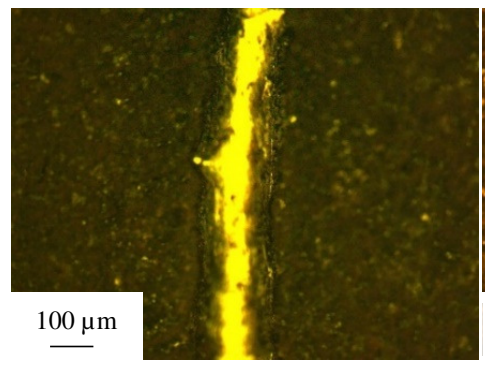

(a)

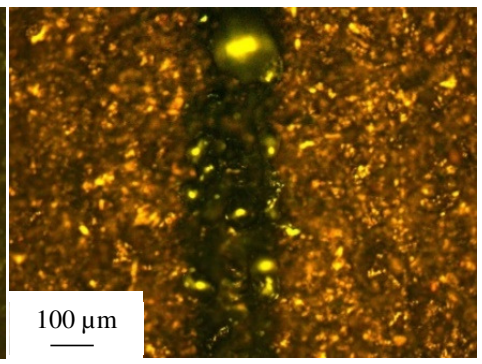

(b)

Fig 9. Selective laser melting using $350 \mathrm{~W}$ laser power and $400 \mathrm{~mm} / \mathrm{s}$ scan speed showing (a) pure Ag on steel substrate and (b) pure Ag on copper substrate.

When the laser power was kept constant and scan speed increased from 400 to $1000 \mathrm{~mm} / \mathrm{s}$, the resulting silver single-track was found to be significantly affected as a result of the reducing energy input. For $350 \mathrm{~W}$ laser power, the increased scan speed and reduced energy created a balling effect on the steel substrate and broken or unstable track formation was seen after $500 \mathrm{~mm} / \mathrm{s}$ scan speeds. This indicates that the energy density is lower and there is insufficient contact between the molten material and the steel substrate for efficient molten track formation. The use of pure Ag on copper substrate showed no molten track production except for occasional random melted particles consistent with previous tests.

At a laser power of $370 \mathrm{~W}$ and full scan speed range of 400-1000 mm/s, molten tracks can be seen for pure Ag on the steel substrate. Fig. 10 shows pure Ag molten track produced using $370 \mathrm{~W}$ and $1000 \mathrm{~mm} / \mathrm{s}$ scan speed. A pure silver molten track is produced however the track width is significantly smaller due to the reduced energy input. Fully formed molten tracks were only produced for pure Ag at 350W and scan speeds between 400 and $500 \mathrm{~mm} / \mathrm{s}$ on a steel substrate. Above this speed, the tracks became inhomogeneous with visibly broken tracks. On a copper substrate, no track formation of pure silver was observed, a result consistent with previous attempts. The analysis offered shows that a copper substrate with high heat transfer and 
reflectivity is not a suitable substrate for the SLM of pure Ag single-tracks using one laser pass. The results indicate that a steel substrate is more suitable for single track fabrication of pure $\mathrm{Ag}$ despite the differences in thermal and reflectivity between the two materials. However, this could also suggest that proceeding single tracks and layers of pure $\mathrm{Ag}$ would subsequently fail once the layer height increases beyond the thermomechanical interactions of the steel substrate.

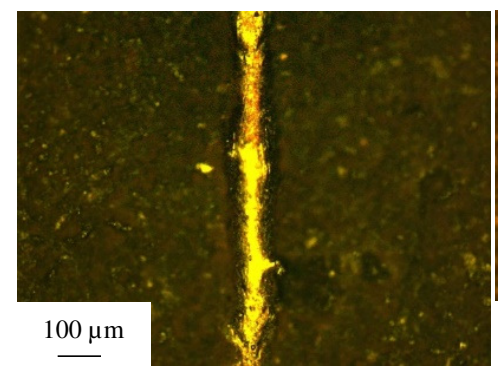

(a)

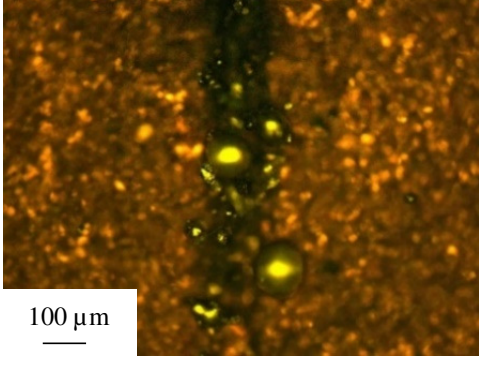

(b)

Fig 10. Selective laser melting at $370 \mathrm{~W}$ laser power and $1000 \mathrm{~mm} / \mathrm{s}$ scan speed showing (a) pure silver on steel substrate and (a) pure silver on copper substrate.

\subsection{Process window for stable track formation}

To identify the optimal scan speeds and laser power required for consistent and controlled molten track fabrication the single tracks were analysed using optical microscopy. Fig 11a shows the average track width measured at a laser power of 350 and $370 \mathrm{~W}$ for the scan speed ranging from 400 to $1000 \mathrm{~mm} / \mathrm{s}$. Track widths reduce as scan speeds increases. This is due to the reduction in energy input at the powder bed resulting in a thinner track width.

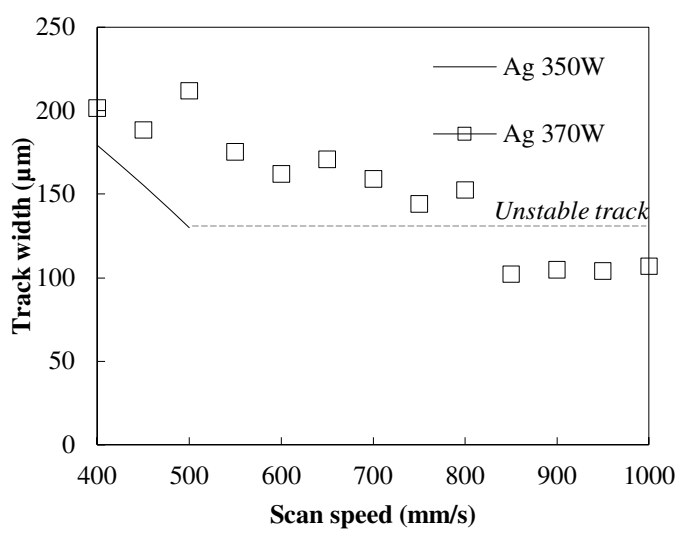

(a)

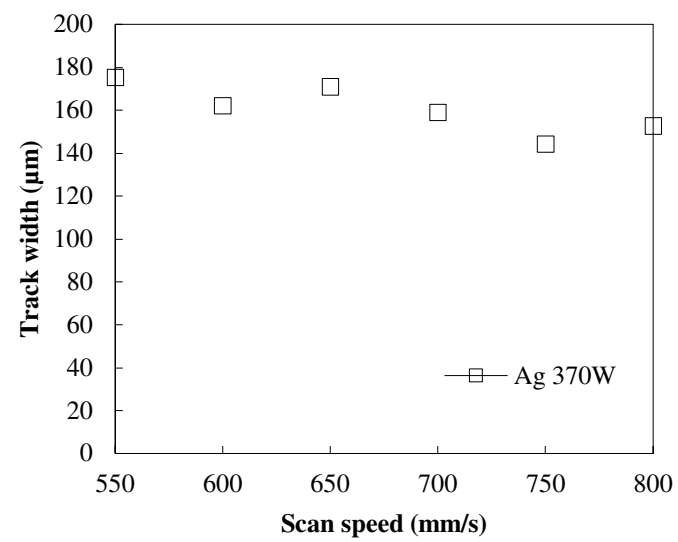

(b)

Fig 1110. Average track width for laser melted pure silver (a) $400 \mathrm{~mm} / \mathrm{s}-1000 \mathrm{~mm} / \mathrm{s}$ scan speeds and $350 \mathrm{~W}$ and 370W laser power on steel substrate and (b) Stable track width window observed between 500mm/s and 800mm/s scan speeds.

Above a scan speed of $500 \mathrm{~mm} / \mathrm{s}$, the track formation becomes discontinuous and therefore unmeasurable for $\mathrm{Ag}$ at $350 \mathrm{~W}$, represented by the dotted line (Fig 11a). The most stable molten 
material and pure Ag single-track widths were formed at the highest laser power of $370 \mathrm{~W}$ between scan speeds of 550 and $800 \mathrm{~mm} / \mathrm{s}$ as shown in Fig 11b. Minimal track width variation was observed between these scan speed parameters. Within this range, the maximum variation in track width was $31 \mu \mathrm{m}$.

\subsection{Single track cross section analysis}

Processing atomised pure Ag to create stable molten material single tracks utilising PBF AM systems has been shown to be feasible using the laser power and scan speed parameters discussed. However, single-track fabrication was only possible using a steel build substrate. The copper build substrate had a significant negative effect on the fabrication of pure Ag molten tracks due to its thermomechanical properties. This raised questions as to what happens once the layer-bylayer process has reached a level past the thermomechanical effects of the steel substrate?

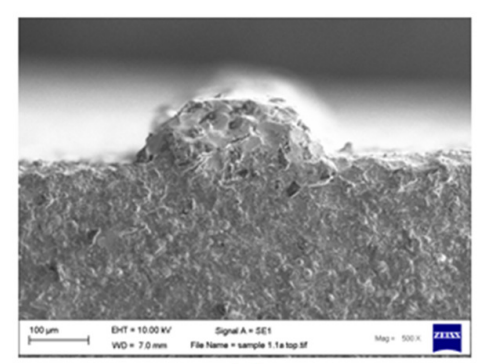

(a)

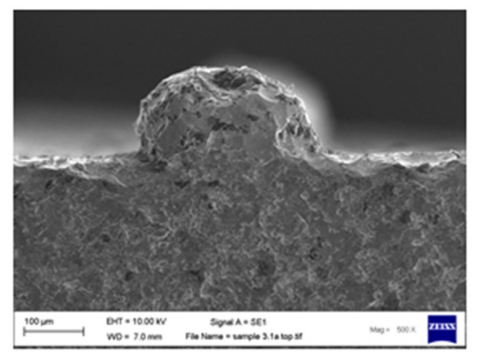

(c)

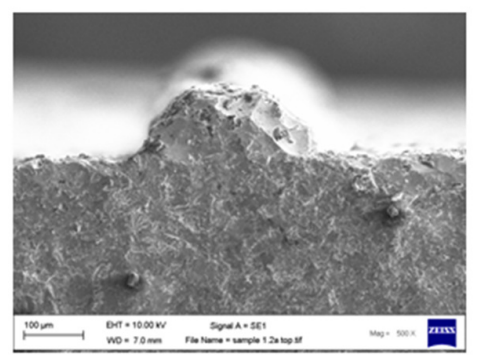

(b)

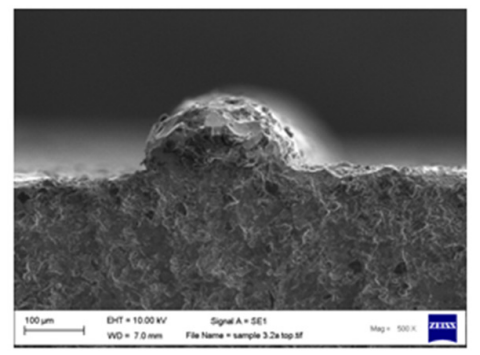

(d)

Figure 12. SEM images of pure Ag single track cross-section manufactured using scan speeds of (a) $400 \mathrm{~mm} / \mathrm{s}$, (b) $450 \mathrm{~mm} / \mathrm{s}$, (c) $500 \mathrm{~mm} / \mathrm{s}$ and (d) $550 \mathrm{~mm} / \mathrm{s}$.

Silver has higher reflectivity and thermal conductive properties than copper, consequently at this stage it could be assumed that post the initial layers, the preceding layers would fail to build due to different thermomechanical behaviour of building pure silver-on - pure silver layers. Laser energy penetration and melt depth are important considerations for the fabrication of dense parts using AM PBF technologies [37]. However, in this case, the penetration depth created by pure $\mathrm{Ag}$ single tracks only offer limited information due to the differences in substrate and processing material properties. Nevertheless, fabricating pure Ag single tracks on steel substrate highlights the potential for 400W 1060-1100 nm wavelength systems to be used to process reflective and thermally conductive materials. The results do not however verify whether 
multilayer pure Ag could be additively manufactured to create 3D structures. Therefore, to ascertain cohesion between the build substrate and single tracks, the cross-section of the samples was analysed as shown in Fig 12 and 13. An electrical discharge machine (EDM) was used to section the tracks and the resulting surfaces analysed using SEM.

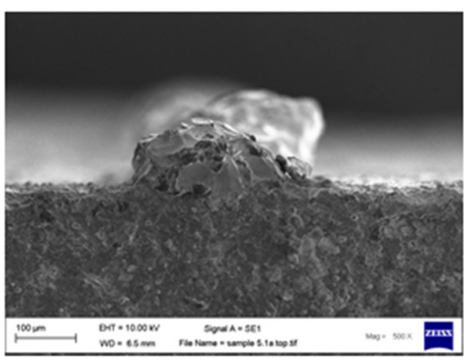

(a)

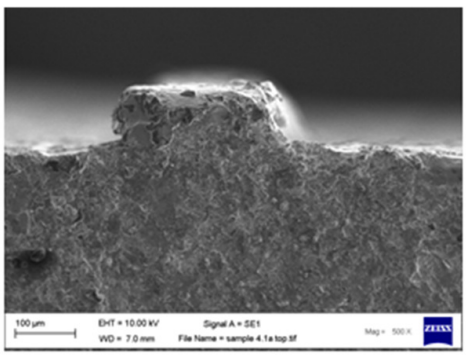

(c)

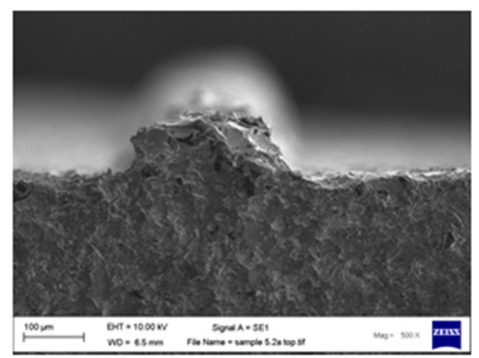

(b)

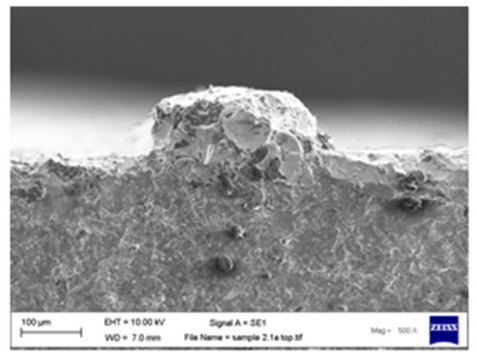

(d)

Figure 13. SEM images of pure Ag single track cross section additive manufactured at laser scan speeds of (a) 600 $\mathrm{mm} / \mathrm{s}$, (b) $650 \mathrm{~mm} / \mathrm{s}$, (c) $700 \mathrm{~mm} / \mathrm{s}$ and (d) $800 \mathrm{~mm} / \mathrm{s}$.

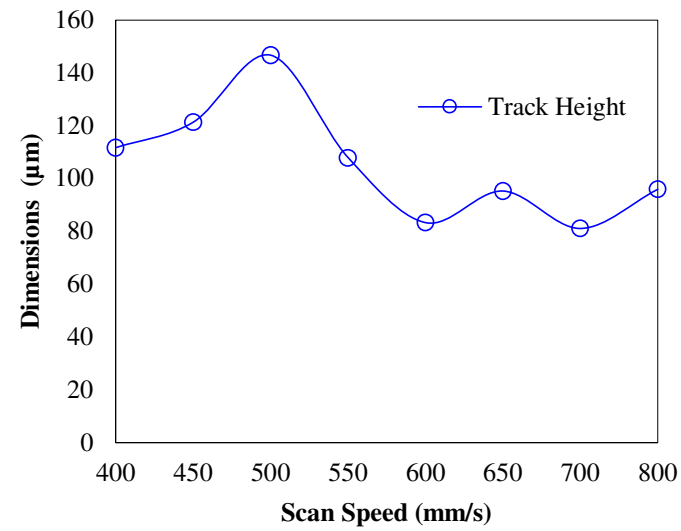

Fig 14. Variation in cross-sectional track height with respect to scan speed.

As can be seen from both Fig 12 and 13, all single tracks appeared fully fused to the steel substrate and no breaks between tracks and build substrates were visible. Penetration depth into the substrate is also not visible and to the most part irrelevant for the reasons discussed above. Cross sectional height of pure Ag single tracks characterised using SEM are presented in 
Fig 14. The results highlight a reduction in track height as scan speeds increase as a result of the reduction of energy input reduction.

The analysis so far shows that laser melting of highly reflective and thermally conductive materials such as pure $\mathrm{Ag}$ to create molten single tracks is feasible utilising PBF AM using a 400W 1060-1100nm wavelength fibre laser. However, the substrate material has a significant effect on molten material and the creation of the molten single tracks in this study is reliant on processing parameters shown in table 1. In addition, the significant influence of substrate material shows that further study is needed in this regard when it comes to laser melting of highly conductive materials such as copper and silver. Cross sectional analysis showed cohesion between pure Ag molten tracks and steel substrate for optimised parameters selected.

Table 1. Requirement for stable track production in 99.9\% Ag using SLM.

\begin{tabular}{lllll}
\hline Sieve dia. & Volume Size Distribution & Laser power & Scan speed & Substrate \\
\hline $50 \mu \mathrm{m}$ & $38.8 \mu \mathrm{m}<90 \%$ PSD $>18.8 \mu \mathrm{m}$ & $370 \mathrm{~W}$ & $550-800 \mathrm{~mm} / \mathrm{s}$ & Steel \\
\hline
\end{tabular}

\subsection{Manufacturing of multilayer strucutres}

SLM of pure Ag to create stable molten tracks has been shown to be feasible using a 400W 1060$1100 \mathrm{~nm}$ wavelength fibre laser system and the parameters described in table 1. Molten singletrack width stability and variations have been discussed and cross section analysed. Results show that $370 \mathrm{~W}$ laser power combined with a range of scan speeds can be used to create cohesive pure $\mathrm{Ag}$ molten material tracks on steel substrate. However, the fabrication of pure Ag components would require the layer-by-layer processing of highly reflective and thermally conductive pure $\mathrm{Ag}$ on pure Ag layers.

The copper build substrate single track results have demonstrated the difficulty of selective laser melting highly reflective and thermally conductive materials. However, using the parameters described in table 1, the feasibility of SLM pure Ag into 3D structures was investigated. Although AM single track fabrication cannot be a true representation of AM component fabrication, the pure Ag and laser interaction results can be analysed for further investigation. Stable molten track formation dimensions taken from Fig 11b reveal the shortest and widest track width limits being 0.14 and $0.175 \mathrm{~mm}$ respectively. Accordingly, these values were used as input for hatch distance investigation from 0.14 to $0.18 \mathrm{~mm}$ at $0.1 \mathrm{~mm}$ increments. The track height measurements ranged from $81 \mu \mathrm{m}$ to $146 \mu \mathrm{m}$ (Fig 14), which is significantly larger than the 30 $\mu \mathrm{m}$ layer thicknesses used for most standard AM materials. Therefore, layer thicknesses of 30 $\mu \mathrm{m}$ and $60 \mu \mathrm{m}$ were investigated to ascertain layer-by-layer interaction and resultant density of SLM pure Ag. For ease of bulk density analysis, the structures were processed with unexposed 
contour parameters. Fig 15 shows the resulting 3D structures where the optimum parameters successfully fabricated both solid cubes and thin walls across all parameter variations at both 30 $\mu \mathrm{m}$ and $60 \mu \mathrm{m}$ layer thicknesses.

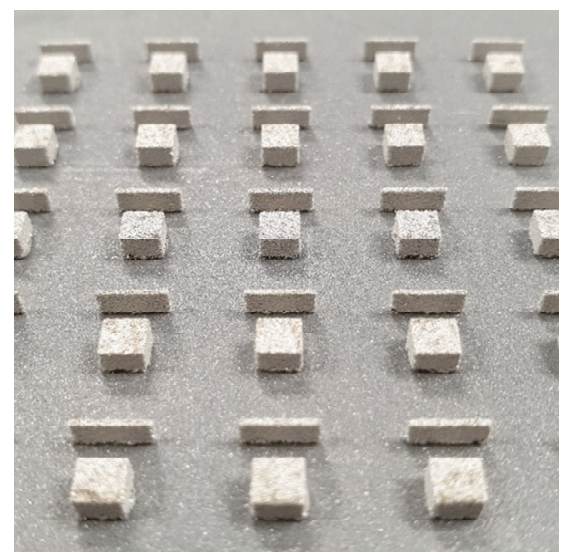

(a)

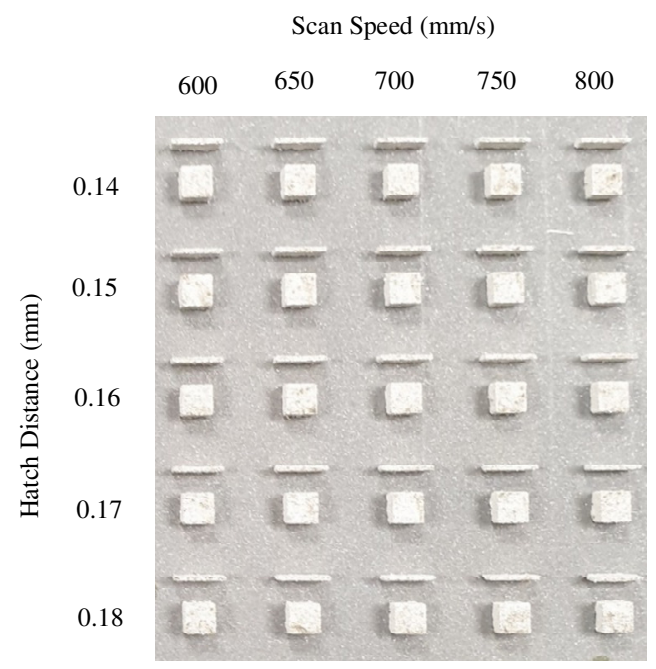

(b)

Fig 15. As built pure Ag structures showing (a) $3 \mathrm{~mm}$ cubes and thin walls at $60 \mu \mathrm{m}$ layer thickness and (b) $3 \mathrm{~mm}$ cubes and thin walls with associated scan speed and hatch distance parameters.

\subsection{Density analysis}

Single track and layer-by-layer interactions and binding mechanisms effect microstructure, density and the associated mechanical properties of PBF fabricated components [32,36,38]. SLM laser power, scan speed and hatch distance parameters effect energy density at the powder bed and therefore are common process parameters adjusted for process optimisation [38,39]. Incorrect or un-optimised process parameters can lead to unstable and inconsistent single-track formation as demonstrated in this study, which in turn lead to weak interlayer bonding, part defects and porosity. Porosity in SLM components is well understood $[23,34,40,41]$, the reasons for which range from lack of fusion along with blowhole and keyhole cavities [42,43]. Keyhole and blowhole (trapped gas) porosity appear as closed spherical porosity voids (enclosed with dense material), while lack of fusion (unmolten material) appears as irregular shaped porosity voids either closed (surrounded by dense material) or open where the porosity is near the surface $[42,43]$. Understanding the type and content of porosity is crucial for further parameter development towards the fabrication of dense parts. Accordingly, pure Ag porosity type and content was characterised using optical and scanning electron microscopy.

Fig. 16 presents the density and porosity content of $3 \mathrm{~mm}$ cubes at $30 \mu \mathrm{m}$ layer thicknesses for a scan speed range and hatch distance of $600-800 \mathrm{~mm} / \mathrm{s}$ and $0.14-0.18 \mathrm{~mm}$ respectively. Although $3 \mathrm{~mm}$ cube structures were successfully built for all parametric ranges, a significant variation in 
material density can be observed. Irregular shaped porosity voids can be seen in the majority of samples, which would suggest lack of fusion porosities due to unmolten material. This is particularly evident in $0.16 \mathrm{~mm}$ hatch distance and $700 \mathrm{~mm} / \mathrm{s}$ scan speed however all samples showed this porosity void type. Smaller spherical porosity surrounded by dense areas are also visible which suggests the presence of keyhole and blow hole porosity.

600
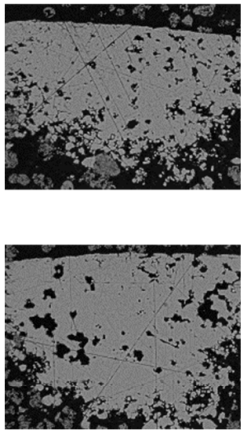

.16
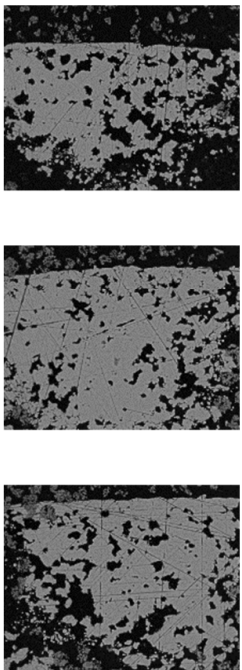

650
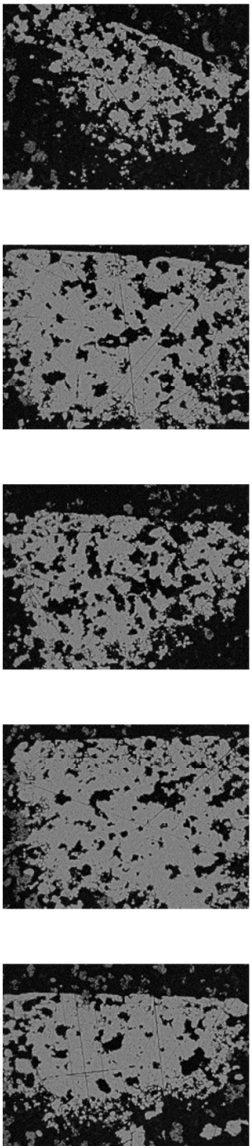

700
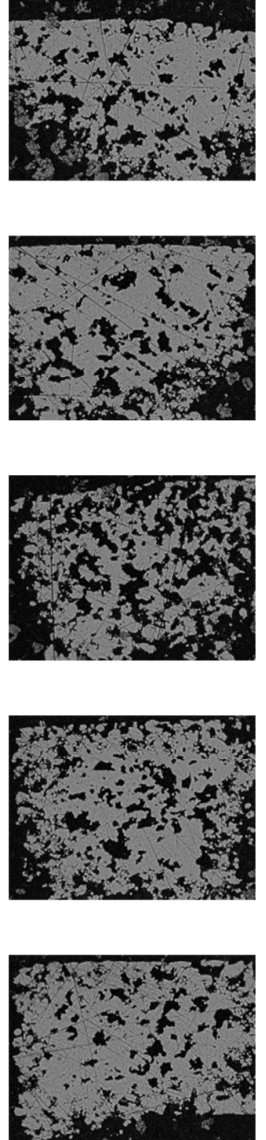

750
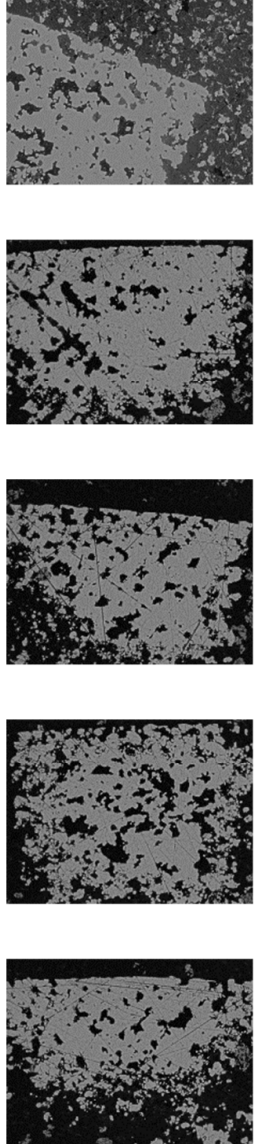

800
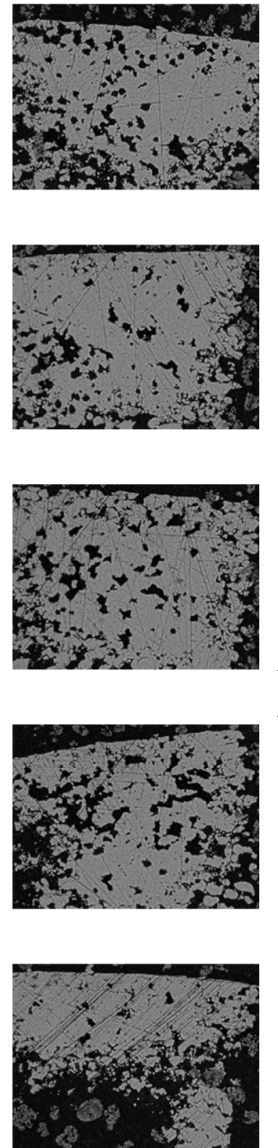

Scan Speed $(\mathbf{m m} / \mathbf{s})$

Fig 16. Density variation of laser melted $3 \mathrm{~mm}$ pure silver cubes additively manufactured at $30 \mu \mathrm{m}$ layer thickness.

Fig. 17 presents the density and porosity content of $3 \mathrm{~mm}$ cubes at $60 \mu \mathrm{m}$ layer thicknesses for the same scan speed and hatch distance ranges of $600-800 \mathrm{~mm} / \mathrm{s}$ and $0.14-0.18 \mathrm{~mm}$. It can be seen that structures were successfully built at all parameter ranges considered. Nevertheless, layer thickness can be seen to have a significant effect on the resulting material density with high porosity content as compared to 30um layer thickness (Fig. 16). This can be attributed to the reduced laser energy absorption and re-melt depth due to the larger layer thicknesses resulting in lack of fusion porosities. The higher irregular shaped pore sizes observed for a layer thickness of $60 \mu \mathrm{m}$ in comparison to $30 \mu \mathrm{m}$ indicates lack of fusion porosities. Overall, $60 \mu \mathrm{m}$ layer thickness results in a significant increase in lack of fusion (irregular shaped) porosity content and was disregarded for further analysis. 
600

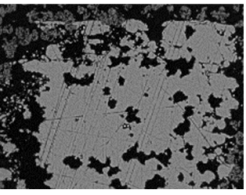

.15

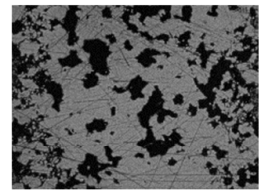

0.16

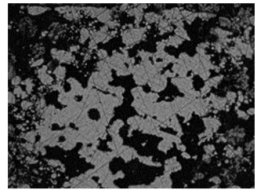

0.17

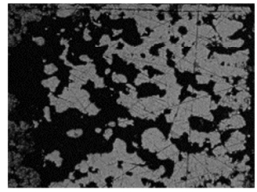

0.18

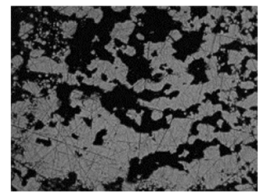

650
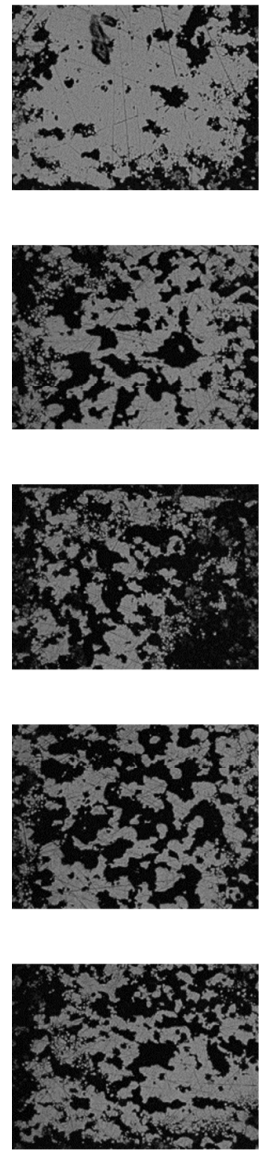

700
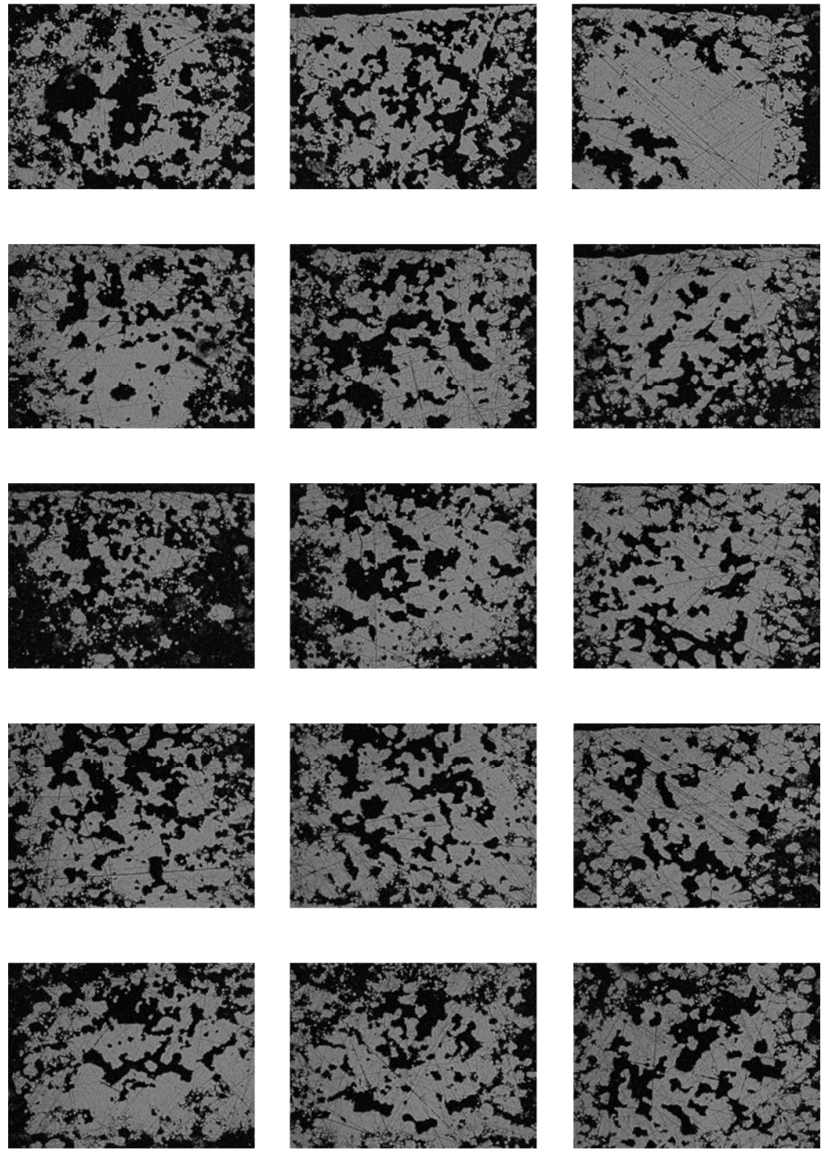

Scan Speed $(\mathrm{mm} / \mathrm{s})$

Fig 17. Density variation of $3 \mathrm{~mm}$ pure silver cubes additively manufactured at $60 \mu \mathrm{m}$ layer thickness.

To further analyse porosity type SEM characterisation of pure Ag structures manufactured at $30 \mu \mathrm{m}$ was completed and images presented in Fig 18. As shown, different porosity types were observed for the pure Ag cubes fabricated depending on the hatch distance and scan speeds. Higher magnification under SEM clearly show lack of fusion porosities with powder particles contained within the porosity voids. This highlights that process parameters (hatch distance and scan speed) have a significant effect on 3D structure and there are areas of the build where laser energy was insufficient to produce fully molten dense material. However, further process parameter optimisation could be conducted to increase the laser energy at the powder bed to reduce lack of fusion porosities. These parameters were also found to result in significant gas entrapment (keyhole or blowhole) spherical porosities which can be created as part of the SLM process. Fig. 18b highlights spherical (gas trapped) and nonuniform (lack of fusion) porosity voids. However, there is a significant reduction in content and size of gas trapped porosities that are observed when compared to Fig. 18a. 


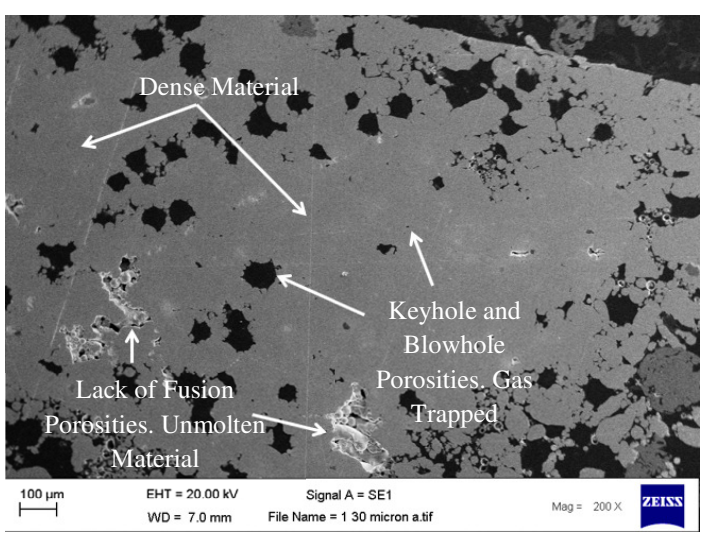

(a)

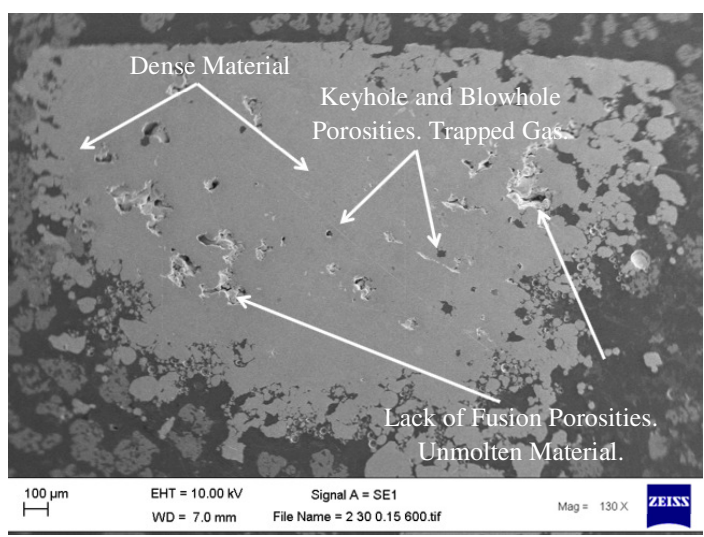

(b)

Fig. 18. Pore types observed for laser melted pure Ag at $30 \mu \mathrm{m}$ layer thickness for (a) $800 \mathrm{~mm} / \mathrm{s}$ scan speed and 0.14 hatch distance and (b) $600 \mathrm{~mm} / \mathrm{s}$ scan speed and 0.15 hatch distance.

While further process parameter optimisation including smaller layer thickness, decreased stripe width, increased laser power and different scan strategies are necessary to reduce lack of fusion porosity, this paper demonstrates that SLM of pure Ag using PBF AM and 400W laser is feasible. Overall, for the best performing layer thickness $(30 \mu \mathrm{m})$, the porosity of the structures ranged from 2.72-34.01\% as summarised in Fig. 19a. The highest density was observed at a hatch distance of $0.15 \mathrm{~mm}$. Looking at the equivalent maximum pore sizes with respect to hatch

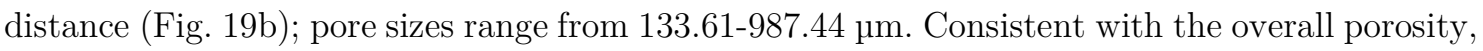
the $0.15 \mathrm{~mm}$ hatch distance was found to have the lowest pore size as well.

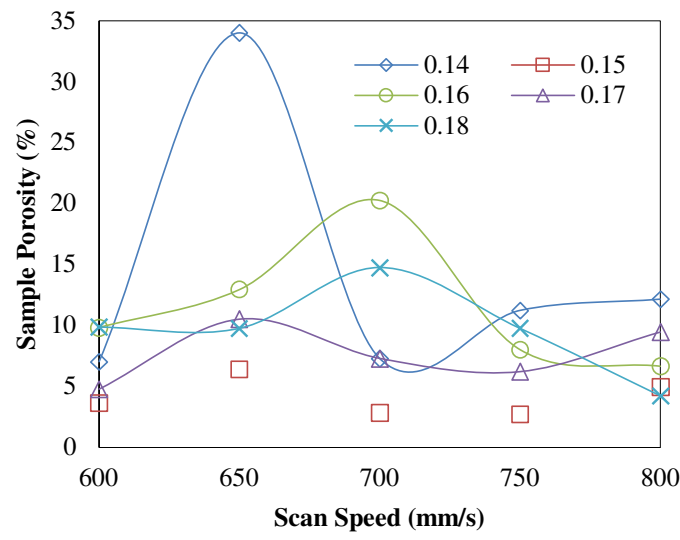

(a)

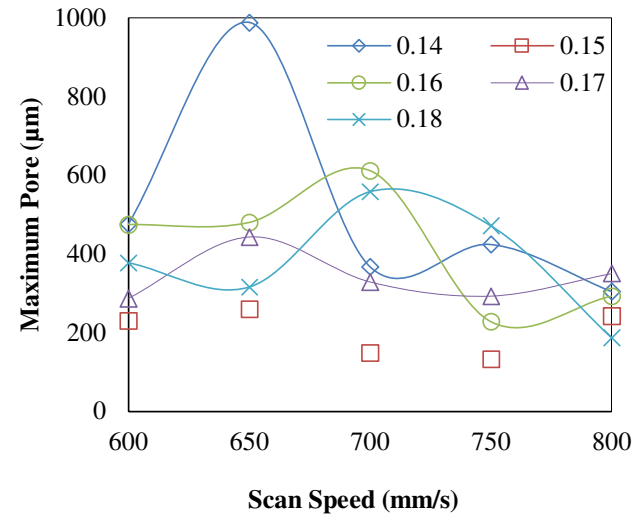

(b)

Fig. 19. Influence of scan speed and hatch distance on laser melted $3 \mathrm{~mm}$ pure silver cubes at $30 \mu \mathrm{m}$ layer thickness showing (a) sample porosity and (b) maximum pore size. 


\section{Conclusion}

This study presents the Selective Laser Melting of (SLM) of pure silver (Ag) using a $400 \mathrm{~W}$ 1060-1100 nm fibre laser Powder Bed Fusion (PBF) Additive Manufacturing (AM) system featuring a $100 \mu \mathrm{m}$ laser spot size. Pure Ag powder was characterised for morphology, particle size and distribution including moisture content, apparent and tap density. The results show that the laser melting of highly conductive and reflective atomised $99.9 \%$ pure $\mathrm{Ag}$ is possible. The most stable tracks were produced at $370 \mathrm{~W}$ and lower scan speeds on steel substrate referring to a requirement of high energy density. Although molten material tracks could be produced at faster scan speeds, the tracks were non-uniform showing breakage and balling. The most stable pure Ag tracks were observed between 550 and $800 \mathrm{~mm} / \mathrm{s}$ scan speeds with an average track width deviation of $31 \mu \mathrm{m}$. The average track width decreased with increasing scan speed resulting in unstable track formation at high speeds such as $1000 \mathrm{~mm} / \mathrm{s}$. The use of copper substrate was found to be unsuitable for the laser melting of pure $\mathrm{Ag}$ despite the comparable thermal properties. Investigating the effect of process parameters on the manufacture of $3 \mathrm{D}$ silver structures, the highest density $(\sim 97 \%)$ was observed at a layer thickness, scan speed and hatch distance of $30 \mu \mathrm{m}, 700-800 \mathrm{~mm} / \mathrm{s}$ and $0.15 \mathrm{~mm}$ respectively. Nevertheless, under all cases fusion porosities in addition to significant gas entrapment represented by keyhole and blowhole pores were observed. Further to demonstrating the feasibility of SLM pure Ag and deriving optimum process parameters, this study also offers the basis for further research in the areas of powder rheology, substrate melt depth, and laser wavelength absorptivity and reflectivity. Furthermore, the results reported in this work offer the basis for further parametric research toward the fabrication of fully dense silver structures.

\section{Acknowledgements}

This research was supported by the University of Wolverhampton and 6DME Ltd.

\section{Data availability}

The data that supports the findings of this study are available from the corresponding author upon reasonable request.

\section{References}

[1] A. Sun, Z. Wu, X. Dong, B. Duan, D. Wang, Effects of Ag addition on electrical and thermal properties of Mo-Cu composites, J. Alloys Compd. 657 (2016) 8-11. doi:10.1016/J.JALLCOM.2015.10.098.

[2] D. Bradley, Silver nanowires, at a stretch: Electronic Materials, Mater. Today. 15 (2012) 361. doi:10.1016/S1369-7021(12)70153-0.

[3] I.A.J. Van Hengel, M. Riool, L.E. Fratila-apachitei, J. Witte-bouma, E. Farrell, A.A. Zadpoor, S.A.J. Zaat, I. Apachitei, Selective laser melting porous metallic implants with immobilized silver nanoparticles kill and prevent biofilm formation by methicillin-resistant Staphylococcus aureus, Biomaterials. (2017). doi:10.1016/j.biomaterials.2017.02.030.

[4] M. Shamsipur, G. Azimi, M.H. Mashhadizadeh, S.S. Madaeni, Selective Transport of Silver Ion 
through a Supported Liquid Membrane Using Hexathia-18-Crown-6 as Carrier., Anal. Sci. 17 (2001) 491-494. doi:10.2116/analsci.17.491.

[5] S. Szemkus, B. Kempf, S. Jahn, G. Wiehl, F. Heringhaus, M. Rettenmayr, Laser additive manufacturing of contact materials, J. Mater. Process. Technol. 252 (2018) 612-617. doi:10.1016/j.jmatprotec.2017.09.023.

[6] S. Maharubin, Y. Hu, D. Sooriyaarachchi, W. Cong, G.Z. Tan, Laser engineered net shaping of antimicrobial and biocompatible titanium-silver alloys, Mater. Sci. Eng. C. 105 (2019) 110059. doi:10.1016/J.MSEC.2019.110059.

[7] D. Bradley, Every silver-lined solar cell: Energy, Mater. Today. 12 (2009) 10. doi:10.1016/S13697021(09)70291-3.

[8] R. Huang, M. Riddle, D. Graziano, J. Warren, S. Das, S. Nimbalkar, J. Cresko, E. Masanet, Energy and emissions saving potential of additive manufacturing: the case of lightweight aircraft components, J. Clean. Prod. 135 (2016) 1559-1570. doi:10.1016/j.jclepro.2015.04.109.

[9] M.K. Thompson, G. Moroni, T. Vaneker, G. Fadel, R.I. Campbell, I. Gibson, A. Bernard, J. Schulz, P. Graf, B. Ahuja, F. Martina, Design for Additive Manufacturing: Trends, opportunities, considerations, and constraints, CIRP Ann. - Manuf. Technol. 65 (2016) 737-760. doi:10.1016/j.cirp.2016.05.004.

[10] J.S. Hötter, M. Fateri, A. Gebhardt, Selective Laser Melting of Metals: Desktop Machines Open up New Chances even for Small Companies, in: Manuf. Sci. Technol. III, Trans Tech Publications Ltd, 2013: pp. 461-465. doi:10.4028/www.scientific.net/AMR.622-623.461.

[11] A. Arjunan, M. Demetriou, A. Baroutaji, C. Wang, Mechanical performance of highly permeable laser melted Ti6Al4V bone scaffolds, J. Mech. Behav. Biomed. Mater. 102 (2020). doi:10.1016/j.jmbbm.2019.103517.

[12] A. Arjunan, Targeted sound attenuation capacity of 3D printed noise cancelling waveguides, Appl. Acoust. 151 (2019) 30-44. doi:10.1016/J.APACOUST.2019.03.008.

[13] Additive Manufacturing UK National Strategy 2018-25 - Additive Manufacturing UK, 2018.

[14] J.Y. Lee, J. An, C.K. Chua, Fundamentals and applications of 3D printing for novel materials, Appl. Mater. Today. 7 (2017) 120-133. doi:10.1016/j.apmt.2017.02.004.

[15] K. Bari, A. Arjunan, Extra low interstitial titanium based fully porous morphological bone scaffolds manufactured using selective laser melting, J. Mech. Behav. Biomed. Mater. 95 (2019) 1-12. doi:10.1016/j.jmbbm.2019.03.025.

[16] A. Arjunan, Acoustic absorption of passive destructive interference cavities, Mater. Today Commun. 19 (2019) 68-75. doi:10.1016/j.mtcomm.2018.12.012.

[17] S.A.M. Tofail, E.P. Koumoulos, A. Bandyopadhyay, S. Bose, L. O'Donoghue, C. Charitidis, Additive manufacturing: scientific and technological challenges, market uptake and opportunities, Mater. Today. 21 (2018) 22-37. doi:10.1016/j.mattod.2017.07.001.

[18] M. Fateri, A. Gebhardt, J.-S. Hötter, M. Knothe, F.M. Schmidt, H. Rieper, Numerical and Experimental Investigation of Selective Laser Melting of Silver, Fraunhofer Direct Digit. Manuf. Conf. (DDMC), Berlin. (2012).

[19] D. Bourell, J.P. Kruth, M. Leu, G. Levy, D. Rosen, A.M. Beese, A. Clare, Materials for additive manufacturing, CIRP Ann. - Manuf. Technol. 66 (2017) 659-681. doi:10.1016/j.cirp.2017.05.009.

[20] A. Vance, K. Bari, A. Arjunan, Compressive performance of an arbitrary stiffness matched anatomical Ti64 implant manufactured using Direct Metal Laser Sintering, Mater. Des. 160 (2018) 1281-1294. doi:10.1016/j.matdes.2018.11.005.

[21] A. Vance, K. Bari, A. Arjunan, Investigation of Ti64 sheathed cellular anatomical structure as a tibia implant, Biomed. Phys. Eng. Express. 5 (2019) 035008. doi:10.1088/2057-1976/ab0bd7.

[22] G. Abbas Gohar, T. Manzoor, A.N. Shah, Investigation of thermal and mechanical properties of $\mathrm{Cu}-\mathrm{Al}$ alloys with silver addition prepared by powder metallurgy, J. Alloys Compd. 735 (2018) 802-812. doi:10.1016/J.JALLCOM.2017.11.176. 
[23] M. Colopi, L. Caprio, A.G.G. Demir, B. Previtali, Selective laser melting of pure Cu with a 1 kW single mode fiber laser, 2018.

https://www.sciencedirect.com/science/article/pii/S221282711830814X (accessed January 19, 2019).

[24] C. Silbernagel, L. Gargalis, I. Ashcroft, R. Hague, M. Galea, Electrical resistivity of pure copper processed by medium-powered laser powder bed fusion additive manufacturing for use in electromagnetic applications, Addit. Manuf. 29 (2019) 100831. doi:10.1016/j.addma.2019.100831.

[25] W. Xiong, L. Hao, Y. Li, D. Tang, Q. Cui, Z. Feng, C. Yan, Effect of selective laser melting parameters on morphology, microstructure, densification and mechanical properties of supersaturated silver alloy, Mater. Des. 170 (2019) 107697. doi:10.1016/j.matdes.2019.107697.

[26] Opportunities for 3D Printing Precious Metals smartech.pdf, (n.d.).

[27] T.M. Wischeropp, C. Emmelmann, M. Brandt, A. Pateras, Measurement of actual powder layer height and packing density in a single layer in selective laser melting, Addit. Manuf. 28 (2019) 176-183. doi:10.1016/j.addma.2019.04.019.

[28] J.H. Tan, W.L.E. Wong, K.W. Dalgarno, An overview of powder granulometry on feedstock and part performance in the selective laser melting process, Addit. Manuf. 18 (2017) 228-255. doi:10.1016/j.addma.2017.10.011.

[29] R. Deffley, D. Manager, metal powders for additive manufacturing performance and consistency required in demanding, Met. Powder Rep. 69 (2014) 14-17. doi:10.1016/S0026-0657(14)70223-1.

[30] T. Na, W. Rae, S. Yang, O. Kwon, J. Min, G. Kim, K. Jung, C. Lee, H. Park, H. Giun, Materials Characterization E ff ect of laser power on oxygen and nitrogen concentration of commercially pure titanium manufactured by selective laser melting, Mater. Charact. 143 (2018) 110-117. doi:10.1016/j.matchar.2018.03.003.

[31] Z. Dong, H. Kang, Y. Xie, C. Chi, X. Peng, Effect of powder oxygen content on microstructure and mechanical properties of a laser additively-manufactured $12 \mathrm{CrNi} 2$ alloy steel, Mater. Lett. 236 (2019) 214-217. doi:10.1016/j.matlet.2018.10.091.

[32] I. Yadroitsev, A. Gusarov, I. Yadroitsava, I. Smurov, Single track formation in selective laser melting of metal powders, J. Mater. Process. Technol. 210 (2010) 1624-1631. doi:10.1016/j.jmatprotec.2010.05.010.

[33] C. Pleass, S. Jothi, Influence of powder characteristics and additive manufacturing process parameters on the microstructure and mechanical behaviour of Inconel 625 fabricated by Selective Laser Melting, Addit. Manuf. 24 (2018) 419-431. doi:10.1016/j.addma.2018.09.023.

[34] P. O'Regan, P. Prickett, R. Setchi, G. Hankins, N. Jones, Metal Based Additive Layer Manufacturing: Variations, Correlations and Process Control, Procedia Comput. Sci. 96 (2016) 216-224. doi:10.1016/j.procs.2016.08.134.

[35] A.A. Aversa, E. Librera, M. Hadi, G. Marchese, D. Manfredi, F. Calignano, S. Biamino, M. Pavese, PT SC, J. Mater. Process. Tech. (2017). doi:10.1016/j.jmatprotec.2017.11.055.

[36] Y. Guo, L. Jia, B. Kong, N. Wang, H. Zhang, Single track and single layer formation in selective laser melting of niobium solid solution alloy, Chinese J. Aeronaut. (2017). doi:10.1016/j.cja.2017.08.019.

[37] X. Nie, H. Zhang, H. Zhu, Z. Hu, L. Ke, X. Zeng, Analysis of processing parameters and characteristics of selective laser melted high strength $\mathrm{Al}-\mathrm{Cu}-\mathrm{Mg}$ alloys : From single tracks to cubic samples, J. Mater. Process. Tech. 256 (2018) 69-77. doi:10.1016/j.jmatprotec.2018.01.030.

[38] A. Aversa, M. Moshiri, E. Librera, M. Hadi, G. Marchese, D. Manfredi, M. Lorusso, F. Calignano, S. Biamino, M. Lombardi, M. Pavese, Single scan track analyses on aluminium based powders, J. Mater. Process. Technol. 255 (2018) 17-25. doi:10.1016/j.jmatprotec.2017.11.055.

[39] R. Guschlbauer, S. Momeni, F. Osmanlic, C. Körner, Process development of 99.95\% pure copper processed via selective electron beam melting and its mechanical and physical properties, Mater. Charact. 143 (2018) 163-170. doi:10.1016/J.MATCHAR.2018.04.009. 
[40] B. Szaraniec, T. Goryczka, Structure and properties of Ti-Ag alloys produced by powder metallurgy, J. Alloys Compd. 709 (2017) 464-472. doi:10.1016/j.jallcom.2017.03.155.

[41] S.C. Cox, P. Jamshidi, N.M. Eisenstein, M.A. Webber, H. Hassanin, M.M. Attallah, D.E.T. Shepherd, O. Addison, L.M. Grover, Adding functionality with additive manufacturing: Fabrication of titanium-based antibiotic eluting implants, Mater. Sci. Eng. C. 64 (2016) 407-415. doi:10.1016/j.msec.2016.04.006.

[42] T. de Terris, O. Andreau, P. Peyre, F. Adamski, I. Koutiri, C. Gorny, C. Dupuy, Optimization and comparison of porosity rate measurement methods of Selective Laser Melted metallic parts, Addit. Manuf. 28 (2019) 802-813. doi:10.1016/j.addma.2019.05.035.

[43] M. Bayat, A. Thanki, S. Mohanty, A. Witvrouw, S. Yang, J. Thorborg, N. Skat Tiedje, J.H. Hattel, Keyhole-induced porosities in Laser-based Powder Bed Fusion (L-PBF) of Ti6Al4V: High-fidelity modelling and experimental validation, Addit. Manuf. (2019) 100835.

doi:10.1016/j.addma.2019.100835. 